\title{
EFFECTIVE ACTIVATION ENERGY IN THE Bi-Sr-Ca-Cu-O SYSTEMS*
}

\author{
S. Sengupta, Donglu Shi, Zuning Wang, and M.Smith \\ Materials Science Division \\ Argonne National Laboratory, Argonne, IL 60439
}

\section{P.J. McGinn}

Department of Electrical Engineering

University of Notre Dame, Notre Dame, IN 46556

The submitted manuscript has been authored
by a contractor of the U.S. Government under
contract No. W-31-109-ENG-38. Accordingly.
the U.S. Government retains a nonexclusive,
royalty-tree license to publish or reproduce the
published form of this contribution, or allow
others to do so, for U.S. Government purposes.

1992 Applied Superconductivity Conference, Chicago, IL, August 24-28, 1992

jmc

\section{DISCLAIMER}

This report was prepared as an account of work sponsored by an agency of the United States Government. Neither the United States Government nor any agency thereof, nor any of their employees, makes any warranty, express or implied, or assumes any legal liability or responsibility for the accuracy, completeness, or usefulness of any information, apparatus, product, or process disclosed, or represents that its use would not infringe privately owned rights. Reference herein to any specific commercial product, process, or service by trade name, trademark, manufacturer, or otherwise does not necessarily constitute or imply its endorsement, recommendation, or favoring by the United States Government or any agency thereof. The views and opinions of authors expressed herein do not necessarily state or reflect those of the United States Government or any agency thereof.

\footnotetext{
${ }^{*}$ Work supported by the U.S. Department of Energy, BES-Materials Sciences under contract \#W-31-109-ENG-38 (DS, SW, MS), and through the Midwest Superconductivity Consortium DOE Grant DE-FG02-90ER45427 (SS, PM).
} 


\title{
EFFECTIVE ACTIVATION ENFRGY IN THE Bi-Sr-Ca-Cu-O SYSTEMS
}

\author{
S. Sengupta, Donglu Shi, Zuning Wang, and M. Smith \\ Materials Science Division, Argonne National Laboratory, Argonne, IL 60439) \\ P. J. McGinn \\ Deparument of Electrical Engineering, University Of NotreDame, NotreDame, IN 46556
}

\begin{abstract}
Magnetic relaxation in the $\mathrm{Bi}-\mathrm{Sr}-\mathrm{Ca}-\mathrm{Cu}-\mathrm{O}$ systems has been investigated in a wide temperature regime. Previously reported studies of the effective activation energy, $\mathrm{U}$, have been controversial in terms of temperature and field dependence of the critical current density, jc. We have considered the temperature dependence of $\mathrm{j}_{\mathrm{c}}$ and constructed the U-j (or M) curves for the Bi-Sr-Ca-Cu-O system. We found that at a constant driving force and temperature, $U$ is considerably higher for 2245 samples than for 2223 samples. This enhancement can be attributed to the flux pinning from finely dispersed calcium- and copper- rich precipitates.
\end{abstract}

\section{INTRODUCTION}

The decay of magnetization with time is a well-known phenomenon in Type-II superconductors [1,2]. Anderson and Kim first explained this phenomenon by using a thermally activated flux-creep model [3]. They assumed that the fluxoid motion is thermally activated and the rate at which the "flux bundles" jump over the pinning barriers can be described by an Arrhenius-type expression

$$
v=v_{0} \exp \{-U(j) / k T\}
$$

where $v_{0}$ is the attempt frequency and $U(j)$ is the effective activation energy. Because of pinning, a non-uniform distribution of vortices exists at the critical state. At the critical state, $\mathrm{j} \sim \mathrm{j}_{\mathrm{c}}$ (where $\mathrm{j}_{\mathrm{c}}$ is the critical current density) and $\mathrm{U}\left(\mathrm{j}_{\mathrm{c}}\right) \sim 0$. As the system relaxes to achieve a uniform distribution of vortices, the current density decays and the activation energy grows. The activation energy gives a measure of the barrier to the flux motion, that is $U(j)$ is small when the system is relaxing quickly, and vice versa. The rate equation can be written as

$$
\mathrm{dj} / \mathrm{dt}=\mathrm{A} \exp (-\mathrm{U} / \mathrm{kT}) .
$$

We now expand $U(j)$ in the neighborhood of some current density jo [4]:

$$
\begin{aligned}
U(j)= & U\left(j_{0}\right)+\left[\partial U / \partial j_{0}\left(j-j_{0}\right)+\right. \\
& 1 / 2\left[\partial^{2} U / \partial j^{2}\right]_{0}\left(j-j_{0}\right)^{2}+\ldots \\
\approx & U\left(j_{0}\right)+\alpha\left(j-j_{0}\right)+\beta / 2\left(j-j_{0}\right)^{2} .
\end{aligned}
$$

Substituting Equation (2) in Equation (3) and integrating between time $t_{0}$ and $t$, one obtains

$$
j(t)=j(0)+a \ln \left(t / t_{0}\right)+b \ln ^{2}\left(t / t_{0}\right)
$$

where $a=k T / \alpha$ and $b=-\left(k^{2} T^{2} / 2 \alpha^{3}\right) \beta$. Both $a$ and $b$ can be determined from magnetic relaxation experiments and used to calculate $\alpha$ and $\beta$. With the knowledge of slope $\alpha$ and curvature $\beta$, one can construct $U-j$ curves using Equation (3) [5].

In this paper we report the U-j curves for $\mathrm{Bi}-\mathrm{Sr}-\mathrm{Ca}-\mathrm{Cu}-\mathrm{O}$ systems in which the pinning energy has been enhanced by introducing a large quantity of calcium- and copper- rich precipitates into the stochiometric compound $\mathrm{Bi}_{2} \mathrm{Sr}_{2} \mathrm{CaCu}_{2} \mathrm{O}_{x}$ (2212). We will show that although $U$ does not give the true pinning energy, $U_{p}$, one can still use the $U_{-j}$ curves for comparative studies, if one considers the temperature dependence of $\mathrm{j} c$. We will also explain the effective activation energy in terms of the decay rate $\sim \mathrm{dj} / \mathrm{dt}$.

\section{EXPERIMENTAL DETAILS.}

Glass samples with the nominal compositions of $\mathrm{Bi}_{2} \mathrm{Sr}_{2} \mathrm{Ca}_{2} \mathrm{Cu}_{3} \mathrm{O}_{x}$ (2223), $\mathrm{Bi}_{2} \mathrm{Sr}_{2} \mathrm{Ca}_{3} \mathrm{Cu}_{4} \mathrm{O}_{x}$ (2234), and $\mathrm{Bi}_{2} \mathrm{Sr}_{2} \mathrm{Ca}_{4} \mathrm{Cu}_{5} \mathrm{O}_{x}$ (2245) were made by the splat quenching method reported earlier by Shi et al [6]. The quenched glass samples were then annealed at $870^{\circ} \mathrm{C}$ in air and then slowly cooled to room temperature.

Magnetic relaxation experiments were performed by using a QUANTUM DESIGN SQUID magnetometer. The samples were zero field cooled to the desired temperature below $T_{c}$. A magnetic field of $0.1 \mathrm{~T}$ was applied after the stabilization of the temperature, and the magnetization was recorded as a function of time. The initial magnetization value was recorded 300 seconds after stabilization of the magnetic field. A scanning length of $3 \mathrm{~cm}$ was used to reduce the effects of field inhomogeneity.

\section{RESULTS AND DISCUSSIONS}

Figures 1 and 2 show hysteresis and $\mathrm{jc}_{\mathrm{c}}$ vs. $\mathrm{H}$ for 2223 (near-stochiometric) and 2245 (off-stochiometric) samples. The grains of the annealed samples appear to be in the shape of thin rectangular plates. The intergranular $\mathrm{j}_{\mathrm{c}}$ was estimated by using standard Bean's model [7]. As evident from Figs.1 and 2, a larger hysteresis and higher $\mathrm{j}_{\mathrm{c}}$ are observed for offstochiometric 2245 compound. It should be noted that both 2223 and 2234 are nominal composition. After quenching and annealing, these samples crystallize and form mostly ihe stochiometric 2212 phase with various amounts of fine (submicron) calcium- andcopper-rich precipitates.

The difference in the $\mathrm{j}_{\mathrm{c}}$ in the 2223 and 2245 samples can be attributed to the large quantity of calcium- and copper-rich precipitates. Extensive Transmission electron microscopy has shown that only a few precipitates exist in the 2223 samples whereas a large anount of fine precipitates was found in the 


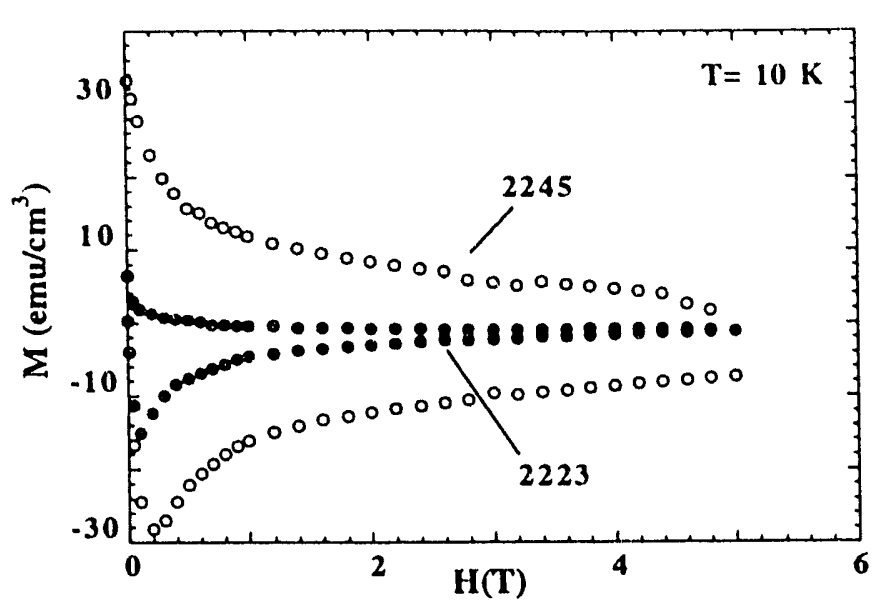

Fig. 1 Magnetic Hysteresis at $10 \mathrm{~K}$ for 2223 and 2245

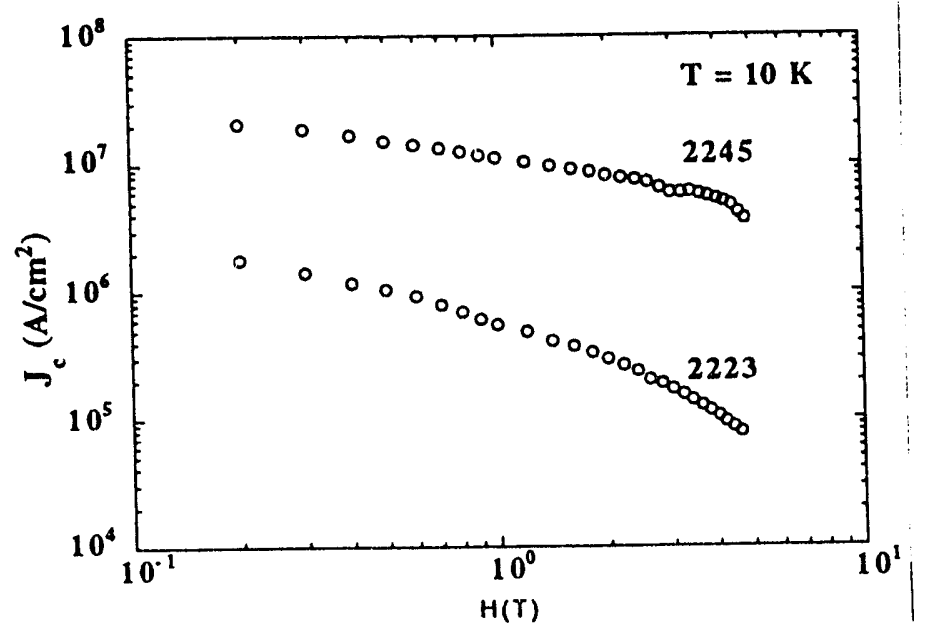

Fig. 2 Critical current density as a function of applied magnetic field at $10 \mathrm{~K}$ for 2223 and 2245 samples

2245 samples [8]. The size of the precipitates varies widely, from less than $0.01 \mu \mathrm{m}$ to almost $0.1 \mu \mathrm{m}$. Many lattice defects such as stacking faults and severe lattice distortion also exist in the 2245 as a result of extra calcium and copper supersaturated in the sample during quenching experiments. It was found that the lattice varied about $8 \%$ between the two local regions separated by approximately $50 \mathrm{~nm}$. This severe lattice distortion did not result in any suppression in $T_{c}$. In contrast, a uniform lattice structure was observed in the 2223 sample, and practically no copper- and calcium-rich precipitates were observed.

Figure 3 shows the U vs. M curves for the 2223 and 2245 compounds obtained by studying isothermal magnetic relaxation at various temperatures using equations (3) and (4).

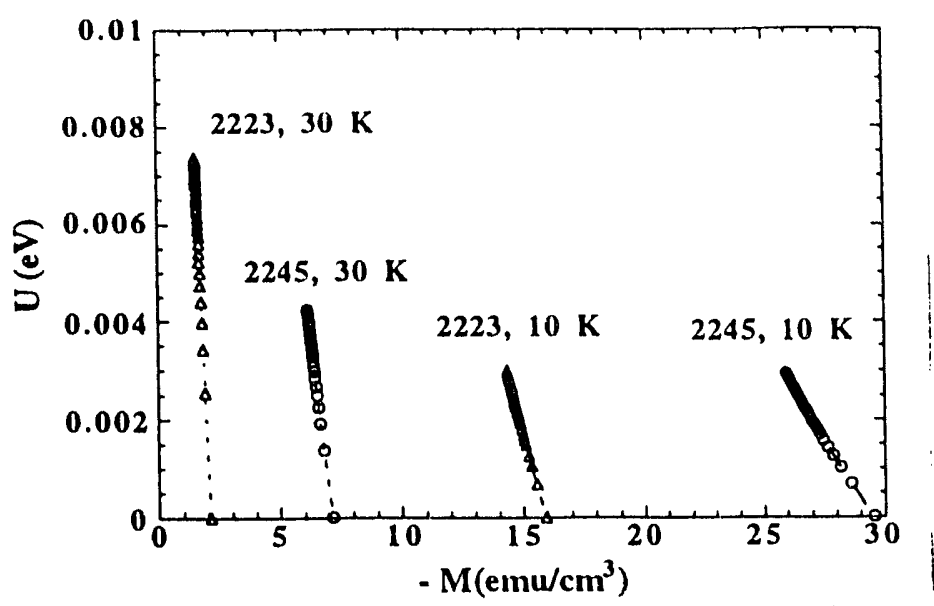

Fig. 3 U vs. M curves for 2223 and 2245 samples at various temperatures. The lines indicate fit to $\ln (-\mathrm{M})$.

It should be noted that $U$ represents the change in activation energy as the magnetization relaxes from $M\left(t=t_{0}\right)$ to $M(t=$ $\left.t_{\text {final }}\right)$. For our experiment $t_{0}=300 \mathrm{~s}$ and $t_{\text {final }}=10500 \mathrm{~s}$. The lines in the figure show a fit with $\ln (-\mathrm{M})$. As we have already shown that if $U$ varies logarithimically with $M$ or $j$, one can then add a constant to the U-M curves at various temperatures to construct $U-M$ or $j$ curves for the lowest temperature [9]. Mathematically one uses the equation

$$
\mathrm{U}\left(\mathrm{M} / \mathrm{M}_{\mathrm{O} 1}\right)=\mathrm{U}\left(\mathrm{M} / \mathrm{M}_{\mathrm{O} 2}\right)+\mathrm{C}\left(\mathrm{M}_{\mathrm{O} 1}, \mathrm{M}_{02}\right) \text {. }
$$

Here $M_{01}$ and $M_{02}$ are the magnetizations for $t=t_{0}$ at $T=T_{1}$ and $T_{2}$, respectively; $T_{1}<T_{2}$. It should be noted that $M_{0}$ is directly related to the critical current density, $j_{c}$, of the material.

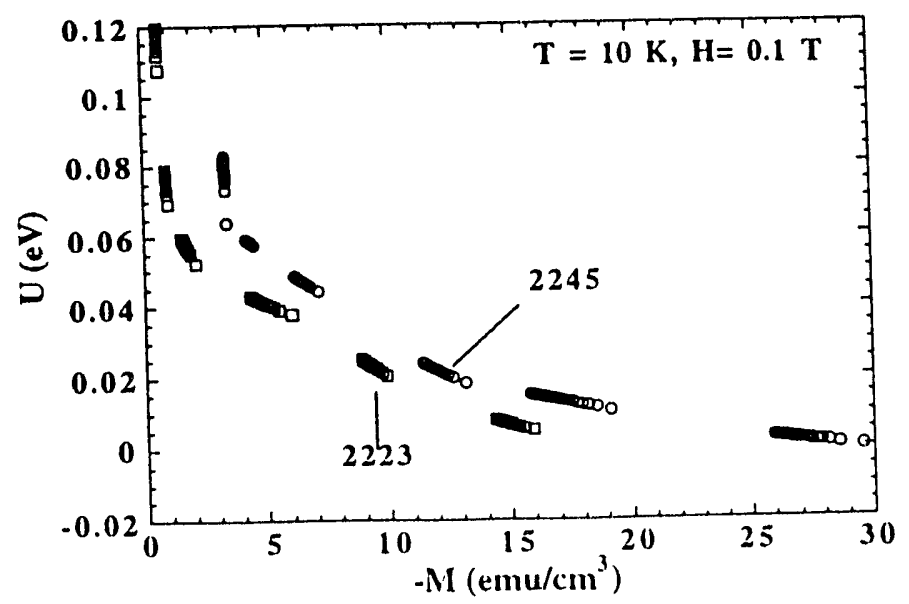

Fig. 4 U vs. M curve for 2223 and 2245 samples at $\mathrm{T}=10$ $\mathrm{K}$. 
Figure 4 shows U vs. $M$ curves at $\mathrm{T}=10 \mathrm{~K}$ for the 2223 and 2234 samples. As we have pointed out earlier, U gives a measure of the barrier to the thux motion and hence does not reflect the true pinning force but rather torces opposing the flux motion. The true pinning energy, $U_{p}$, is more relevant in transport measurements. However, at a given driving force and temperature one can still make a comparative study of two materials. As can be seen from Fig. 4, at a constant driving force (i.e., constant $M$ ) $U$ is higher for the 2245 sample than the 2223 sample. From equation (2) one can say that at the neighborhood of any particular $\mathrm{M}$, the magnetization for the 2223 sample is decaying faster than that of the 2245 sample. This implies that since the thermal energy $\sim \mathrm{kT}$ is same, the vortices are facing a much higher barrier for the 2245 sample than for the 2223 sample. This barrier can be attributed to the flux pinning by the calcium- and copper-rich precipitates and other lattice defects observed in the 2245 sample.

\section{CONCLUSION}

We have studied magnetic relaxation for 2223 and 2245 samples and constructed U-M curves. We have also observed that the 2245 sample has a larger hysteresis and higher $\mathrm{jc}$ than 2223 sample. These results were attributed to the flux pinning by the calcium- and copper-rich precipitates and other lattice defects observed in 2245 sample. This was also reflected in the U-M curves, and we have shown that at a constant $M$, 2245 sample has a higher $U$ than that of 2223 samples.

\section{ACKNOWLEDGMENTS}

This work was supported by the U.S. Department of Energy, Basic Energy Sciences-Materials Sciences, under Contract No. W-31-109-ENG-38 (DS, ZW, and MS). SS and PM acknowledge support from the Midwest Superconductivity Consortium (DOE Contract DE-FG02-90ER45427).

\section{REFERENCES}

[1] M. R. Beasley, R. Labusch, and W. W. Webb, "Flux creep in type-II superconductors," Phys. Rev, vol. 181, pp. 682-700, May 1969.

[2] K. A. Muller, M. Takashige, and J. G. Bednorz, "Flux trapping and superconductive glass state in $\mathrm{La}_{2} \mathrm{CuO} 4-\mathrm{y}: \mathrm{Ba}$," Phys. Rev. Letts., vol. 58, pp. 1143-1146, March 1987.

[3] P. W. Anderson and Y. B. Kim, "Hard superconductivity: Theory of the motion of Abrikosov flux lines, " Rev. Mod. Phys., vol. 36, pp. 39-43, January 1964.

[4] B. M. Lairson, J. Z. Sun, T. H. Geballe, M. R. Beasley, and J. C. Bravman, "Thermal activation of vortex motion in $\mathrm{YBa}_{2} \mathrm{Cu}_{3} \mathrm{O}_{7}-\partial$ films at low temperatures," Phys. Rev. B, vol. 43, pp. 1040510412, May 1991 .

[5] S. Sengupta, Donglu Shi, S. Salem-Sugui, Jr., Zuning Wang, P. J. McGinn, and K. DeMoranville, "Current density dependence of the activation energy in type II superconductors," J. Appl. Phys. vol. 72, pp. 592 595, July 1992.
[6] Donglu Shi, Ming 'Tang, M. S. Boley, Mark Hash, K. Vandervoot, H. Claus, and Y. N. Lwin,

"Crystallization of metal-oxide glassses in Bi-Sr-CaCu-O systems, " Phys. Rev. B, vol. 40, pp. 22472253, August 1989.

[7] C. P. Bean, "Magnetization of hard superconductors," Phys. Rev. Letts, vol. 8, pp. 250252, March 1962.

[8] Donglu Shi, J. G. Chen, U. Welp, Mark S. Boley, and A. Zangvil, "Lattice defects and flux pinning in crystallized metal-oxide glasses in the $\mathrm{Bi}-\mathrm{Sr}-\mathrm{Ca}-\mathrm{Cu}$ O system," Appl. Phys. Lett., vol. 55, pp. 1354-1356, September 1989.

[9] S. Sengupta, Donglu Shi, Zuning Wang, M. E. Smith, and P. J. McGinn, "On the U-j relationship and temperature dependence of $j_{C}$ in type II superconductors," preprint. 

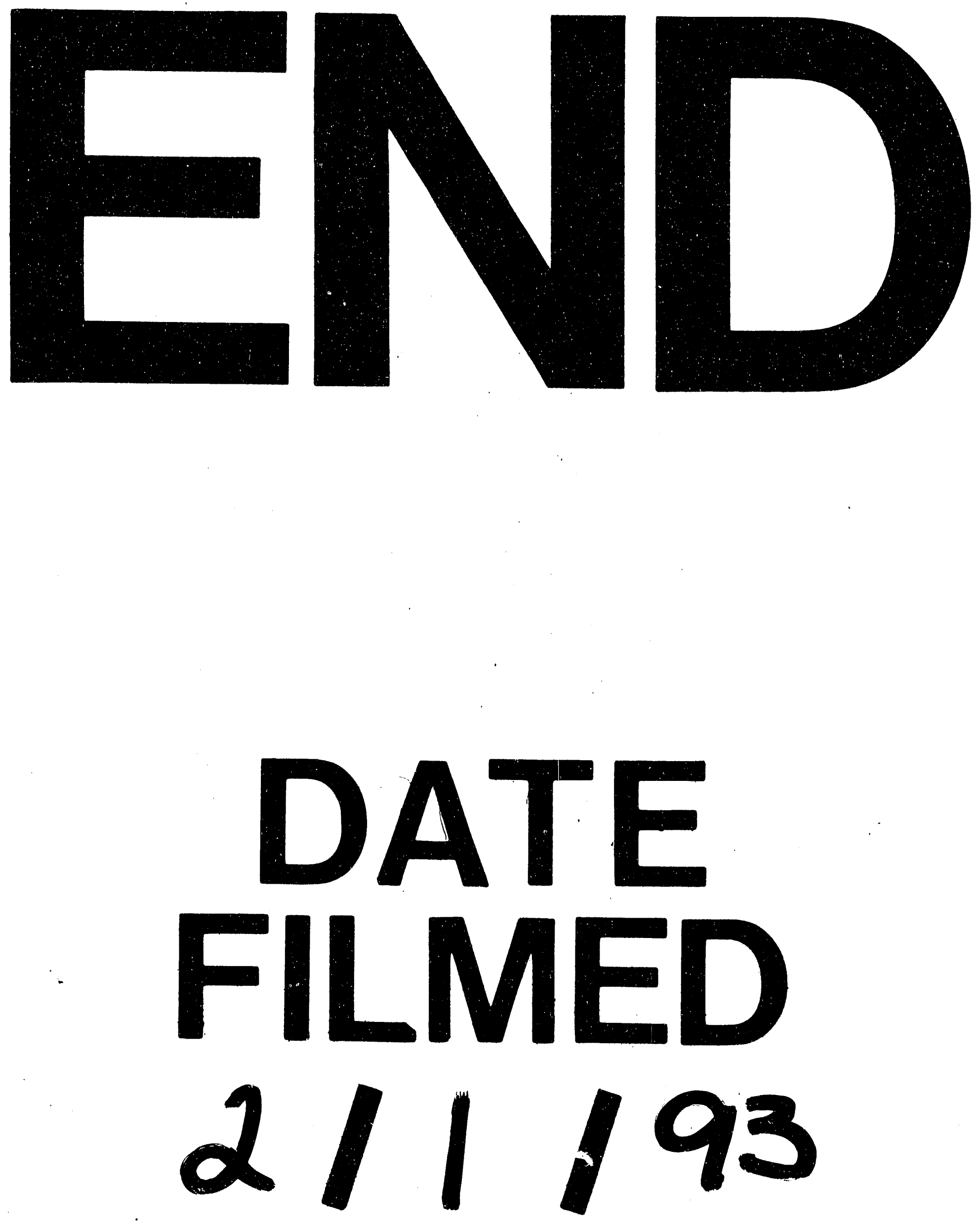
